\title{
Evaluación de los usos del suelo y la erosión hídrica en la subcuenca hidrográfica montañosa del Oued Ourtza (Pre-Rif Oriental, Marruecos)
}

\author{
Land use and hydric erosion assessment in a Mediterranean mountain \\ environment: Case of Wadi Ourtza sub-basin (Eastern-Prerif, Morocco)
}

\author{
Abdellatif Tribak ${ }^{1}$ (i) \\ Rafael Baena-Escudero ${ }^{2}$ \\ Inmaculada Concepción Guerrero-Amador ${ }^{3 *}$ (1) \\ Zakariae Amhani ${ }^{4}$ (D) \\ Mohammed Abahrour ${ }^{5}$ (1) \\ Abdelkader El Garouani ${ }^{6}$ (i) \\ Khalid Arari ${ }^{7}$ (D)
}

\section{Resumen}

Se estudia la distribución espacial de los usos del territorio y de pérdida de suelo en la subcuenca hidrográfica del Oued Ourtza (Pre-Rif Oriental, Marruecos) entre los años 2000 y 2014. Para ello, se ha recurrido a información extraída de imágenes de satélite, el empleo de la ecuación universal de pérdida de suelo en su versión adaptada a las condiciones mediterráneas (RUSLE) y el correspondiente tratamiento mediante herramientas SIG. Las cartografías resultantes denotan la sustitución de los cultivos tradicionales de cereal por otros arbóreos y un importante abandono de las tierras (36,8\%). Las pérdidas de suelo son bastante altas $\left(40 \mathrm{t}^{\mathrm{h}} \mathrm{ha}^{-1} \cdot \mathrm{anno}^{-1}\right)$, muy por encima de su tolerancia, aunque están cercanas a las tasas de ablación registradas en otras áreas del entorno mediterráneo y el Rif marroquí. Estas pérdidas se distribuyen desigualmente, correspondiendo las tasas más elevadas con las tierras no cultivadas o abandonadas $\left(>80 \mathrm{t}^{\cdot} \mathrm{ha}^{-1} \cdot \mathrm{año}^{-1}\right)$ cuya extensión sigue aumentando, sobre todo, en los tramos medio y bajo de la subcuenca donde dominan los materiales lábiles.

Palabras clave: teledetección; erosión; RUSLE; terrenos margosos; norte de Marruecos.

\footnotetext{
Abstract

The spatial distribution of land use and soil loss in the hydrographic sub-basin of the Oued Ourtza (Eastern Prerif, Morocco) between 2000 and 2014 is the subject of this study. We have extracted the thematic information from satellite imagery for the mapping of land occupation and then used geographic information systems for the spatialisation of water erosion according to the universal equation for soil loss in its version adapted to Mediterranean conditions. The resulting maps show an increase in the areas of

1 FLSH-LAGEA Sais-Fès, Université Sidi Mohamed Ben Abdellah Fès, Route d'Imouzzer, BP.59, Fès, Maroc. Abdellatif.tribak@usmba.ac.ma 2 Departamento de Geografía Física y Análisis Geográfico Regional. Facultad de Geografía e Historia, Universidad de Sevilla. C/ María de Padilla s/n 41004, Sevilla. España. baena@us.es

3 Departamento de Geografía Física y Análisis Geográfico Regional. Facultad de Geografía e Historia, Universidad de Sevilla. C/ María de Padilla s/n 41004, Sevilla. España. inmaguer@us.es. * Autora para corrrespondencia

4 FLSH-LAGEA Sais-Fès, Université Sidi Mohamed Ben Abdellah Fès, Route d'Imouzzer, BP.59, Fès, Maroc. Zakariae.amhani@usmba.ac.ma

5 Departament de Géographie, Faculté poly-disciplinaire-USMBA- Taza, Maroc. mohammed.abahrour@usmba.ac.ma

6 Faculté des Sciences et Techniques -USMBA-. Route d'Imouzzer, BP. 2202, Fès, Maroc. abdelkader.elgarouani@usmba.ac.ma

7 FLSH-LAGEA Sais-Fès, Université Sidi Mohamed Ben Abdellah Fès, Route d'Imouzzer, BP.59, Fès, Maroc. Khalid.arari@usmba.ac.ma 


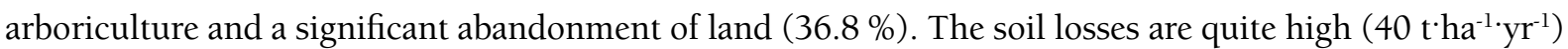
and well above the tolerance threshold; although they are similar to ablation rates in some areas of the Mediterranean environment and the Moroccan Rif. These losses are unevenly distributed, with the highest rates corresponding to uncultivated or abandoned land $\left(>80 \mathrm{t}^{\cdot h \mathrm{~h}^{-1}} \mathrm{yr}^{-1}\right)$ whose extension continues to increase, especially in the middle and lower reaches of the sub-basin where fragile materials dominate.

Keywords: remote sensing; soil erosion; RUSLE; marly lands; northern Morocco.

\section{Introducción}

Los ambientes mediterráneos son particularmente propensos a la erosión del suelo debido a la elevada intensidad de la precipitación, la fragilidad de los suelos, la presencia de fuertes pendientes, pero sobre todo a la larga historia de transformación del paisaje que incluye deforestación, incendios, y frecuentes cambios en el uso de la tierra y los cultivos (Poesen \& Hooke, 1997; Wainwright \& Thornes, 2004 y García-Ruiz, 2010). En relación a esto último, parece evidente que las tasas de pérdida de suelo disminuyen considerablemente a medida que aumenta y se gestiona la cobertura vegetal de los cultivos (Renard, Foster, Weesies \& Porter, 1991; Panagos et al., 2015a), frente a los valores máximos que se obtienen en las zonas de barbecho desnudas (Kinnell, 2010).

En España, el estudio de la erosión en pequeñas cuencas se viene realizando desde los años 80 (p.e. La Roca, 1984; Francis, 1986; Sala, 1988; Romero Díaz, López Bermúdez, Thornes, Francis \& Fisher, 1988; López Bermúdez, 1989), con métodos y resultados muy variados que dificultan su comparación pero que, al menos, han servido para poner de manifiesto la existencia del riego de erosión acelerada en el entorno mediterráneo y establecer unos valores y causas de referencia (García-Ruiz, 2010). La aplicación de métodos empíricos o paramétricos (USLE, RUSLE, CORINE, etc.) junto con otros indirectos a partir de la colmatación de embalses (degradación específica), se muestran como los mejores sistemas para la evaluación rápida y fiable de cuencas hidrográficas. Pero es sin duda el enfoque RUSLE el que ofrece mejor información sobre pérdida de suelo según tipos de cultivo (Van der Knijff, Jones \& Montanarela, 2000; Toubal, Achite, Ouillon \& Dehni, A., 2018), siendo ampliamente utilizado en el ámbito mediterráneo (Ramos \& Porta, 1994). A modo de ejemplo, entre los múltiples que existen, mencionar los resultados obtenidos en diferentes zonas de clima mediterráneo de la Península Ibérica. Así, en la Depresión del Guadalquivir, sobre subcuencas hidrográficas cultivadas de cereal próximas a los macizos subbéticos de Córdoba y Jaén, se alcanzaron valores máximos de erosión estimada (USLE adaptada) de entre 47,7 y 67 $\mathrm{t} \cdot \mathrm{ha}^{-1} \cdot \mathrm{año}^{-1}$ para situaciones de degradación de la cubierta natural o desajustes en los cultivos respecto a la distribución temporal de los episodios de lluvia equinocciales (Moreira Madueño, 1991). En Navarra, mediante mediciones en campo (micro-perfiladores) también en subcuencas cultivadas de cereal, las pérdidas fueron más variadas, oscilando entre 2 y $115 \mathrm{t}^{\cdot} \mathrm{ha}^{-1} \cdot \mathrm{anno}^{-1}$, coincidiendo los máximos con uno o dos eventos intensos de precipitación a finales de otoño o verano (De Santiesteban, Casalí \& López, 2006). Por su parte, en subcuencas hidrográficas dominadas por la arboricultura, los datos obtenidos mediante

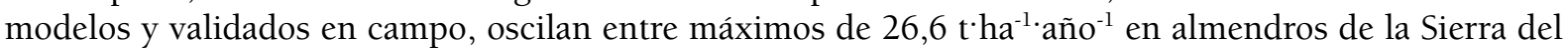
tramo alto del Río Guadaletín en Murcia (Van Wesemael et al., 2006), hasta otros mínimos de 4 t ha $a^{-1} \cdot a-$ $\tilde{n}^{-1}$ en olivar tradicional sobre suelo vértico en el sur de España. En estos últimos destaca la alta variación que registran según el tipo de labranza, con tasas menores y un 7,4\% de coeficiente de escorrentía para la tradicional, mientras que en los tratados con herbicidas los valores se duplican $\left(8,5 \mathrm{t}^{\cdot} \mathrm{ha}^{-1} \cdot \mathrm{año}^{-1}\right)$ y los coeficientes de escorrentía se triplican, alcanzando el 21,5 \% (Gómez, Romero, Giráldez, \& Fereres, 2004).

A nivel europeo, las últimas evaluaciones globales de pérdida de suelo mediante modelo RUSLE, coinciden en señalar a las zonas de clima Mediterráneo y entorno montañoso alpino (Apeninos, Pirineos, Cordilleras Béticas, Cárpatos, etc.) como las más destacadas en tasas medias de erosión (Panagos et al., 2015b). En ellas, cultivos permanentes (viñedos y olivar) y pastizales son los usos más proclives a la erosión, sin embargo los valores máximos ( $\left.>50 \mathrm{t} \cdot \mathrm{ha}^{-1} \cdot \mathrm{año}\right)$, se asocian a zonas de badlands del sureste español con pastizales y terrenos incultos de escasa vegetación (Panagos et al., 2015b). A este respecto, no hay que olvidar, por su relevancia en el incremento de estos valores, el papel desempeñado por el fenómeno del abandono de las tierras de cultivo (e.j. García-Ruiz et al., 1991; García-Ruiz \& Lasanta, 1994; Robledano et al., 2014), sobre todo en zonas de montaña con litologías lábiles o cuencas sedimentarias, donde genera un aumento en los procesos de erosión y degradación de los suelos que, de no ir acompañado de medidas correctoras, puede ser responsable de la generación del modelado de badlands y finalmente, la desertificación (López Bermúdez, 1989; Ruiz Flaño, 1993; Romero Díaz, 2003; Moreno de las Heras et al., 2019). 
En Marruecos, la erosión del suelo representa un problema crucial por las múltiples consecuencias que conlleva (degradación del suelo, baja productividad, colmatación de embalses, cambios en la morfología fluvial, etc.). Según el plan nacional de ordenación de las cuencas hidrográficas, de los 20 millones de hectáreas que se sitúan aguas arriba de las presas en sus respectivas cuencas hidrográficas, alrededor de 5 millones presentan riesgos importantes de erosión hídrica (MADREF, 2001). En el norte de Marruecos, la magnitud de la erosión hídrica es muy elevada con una degradación específica que supera las $2 \mathrm{t} \cdot \mathrm{ha}^{-1}$. año ${ }^{-1}$ (MAMVA, 1993), concentrándose el 60\% de los terrenos erosionados en las montañas del Rif (Heusch, 1990). Aquí, la cuenca hidrográfica del Oued Telata (Rif occidental), aguas arriba de la presa de Ibn Batouta, alcanza

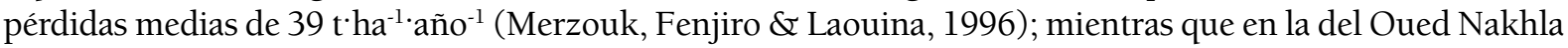
Wadi, han sido estimadas, de manera experimental, en unas $65 \mathrm{t} \cdot \mathrm{ha}^{-1} \cdot \mathrm{año}^{-1}$ (Naimi, Tavaa \& Macaire, 2004). Por su parte, el Rif oriental se presenta en parecidos términos con pérdidas del orden de las $55 \mathrm{t}^{\cdot} \mathrm{ha}^{-1} \cdot \mathrm{año}^{-1} \mathrm{en}$ la cuenca del Oued Boussouab, según el modelo RUSLE (Sadiki, Bouhlassa, Auaijar, Faleh \& Macaire, 2004). Respecto al Pre-Rif, la existencia de cuencas margosas periféricas con materiales lábiles (Oued Ourgha), carentes de vegetación y donde son frecuentes los eventos pluviométricos de alta intensidad, arrojan cifras similares de hasta $60 \mathrm{t}^{\cdot} \mathrm{ha}^{-1} \cdot \mathrm{año}^{-1}$ con variaciones de entre 18 y $109 \mathrm{t}^{\mathrm{h}} \mathrm{ha}^{-1} \cdot \mathrm{año}^{-1}$ dependiendo de las laderas (Lelandais \& Fabre, 1996). A nivel de degradación específica, la cuenca hidrográfica del Oued Lebène (PreRif), presenta variaciones considerables de entre 1,4 y más de $35 \mathrm{t}^{\cdot} \mathrm{ha}^{-1} \cdot \mathrm{anno}^{-1}$, según sea seco o húmedo el periodo considerado (Gartet, 1994).

En este estudio se ha analizado una subcuenca hidrográfica situada al norte de Taza, al representar un medio frágil y vulnerable en un contexto geológico complejo de cabalgamientos con predominio de materiales lábiles y con una fuerte influencia humana responsable de las diferentes modalidades de uso de los suelos. Por ello, se pretende evaluar dentro de la subcuenca hidrográfica del Oued Ourtza, los cambios en la distribución espacial de las áreas de cultivo y su abandono, cuantificando su erosión hídrica potencial entre los años 2000 y 2014, con base en la Ecuación Universal de Pérdida de Suelo en su versión adaptada a las condiciones mediterráneas (RUSLE). A este respecto, dos hipótesis se plantean en este trabajo: (i) que las fuertes pérdidas de suelo corresponden, desde el punto de vista del uso de estos, a terrenos que no son cultivados o han sido abandonados; y (ii) si frente a ello, la extensión considerable de la oleicultura durante las últimas décadas puede contribuir a reducir las tasas de erosión, incluso para aquellos terrenos cultivados en pendiente.

\section{Metodología}

\section{1. Área de estudio y caracterización}

La subcuenca hidrográfica del Oued Ourtza, con una superficie de $73,47 \mathrm{~km}^{2}$, está situada en el PreRif oriental al norte de Marruecos. Se trata de la cabecera del Río Sebou el más importante del norte de Marruecos que desemboca en el océano Atlántico a la altura de la ciudad de Kenitra. Esta subcuenca ocupa una posición baja a nivel de la cuenca hidrográfica del Oued Lahdar, uno de los más importantes afluentes del Oued Inaouene (Figura 1). Tiene forma alargada en dirección nordeste-sudoeste y se caracteriza por una topografía accidentada de colinas y montañas bajas que presentan un modelado de vertientes irregulares respecto al dispositivo estructural y la importante disección fluvial heredada del Cuaternario. Dentro de ella, las altitudes varían entre los más de $1.000 \mathrm{~m}$ que se alcanzan al norte, en el pico más elevado (J. Azdem, $1.373 \mathrm{~m}$ ), y al noreste (J. El Hallaya, $1.310 \mathrm{~m}$ ), y los $430 \mathrm{~m}$ del punto más bajo situado en el exhutorio de la subcuenca.

La geología muestra un claro predominio de los terrenos margosos cenozoicos en un contexto estructural marcado por los mantos de corrimiento (Leblanc, 1979). Las series margosas autóctonas datadas en el Cretáceo y sobre todo de finales del Cenozoico, ocupan la casi totalidad de su superficie, estando en parte sobremontadas por formaciones areniscosas y conglomeráticas que arman particularmente las cumbres de las unidades alóctonas desplazadas. Esto explica el modelado de erosión diferencial que se produce entre las litologías resistentes y lábiles tanto al norte, como en el centro y sur de la subcuenca hidrográfica y que queda reflejado en la distribución en bandas este-oeste que adquieren las zonas con pendientes más fuertes ( $>25 \%$ ) y respecto a las cuales la red hídrica principal se muestra disconforme (Figura 2). Los suelos que se derivan de estas litologías son poco evolucionados por la erosión sobre pendientes pronunciadas. En las depresiones y zonas menos accidentadas aparecen también vertisoles y suelos calcimagnésicos. 
Figura 1. Localización del área de estudio y relieve de la subcuenca hidrográfica del Oued Ourtza (Pre-rif oriental, Marruecos)

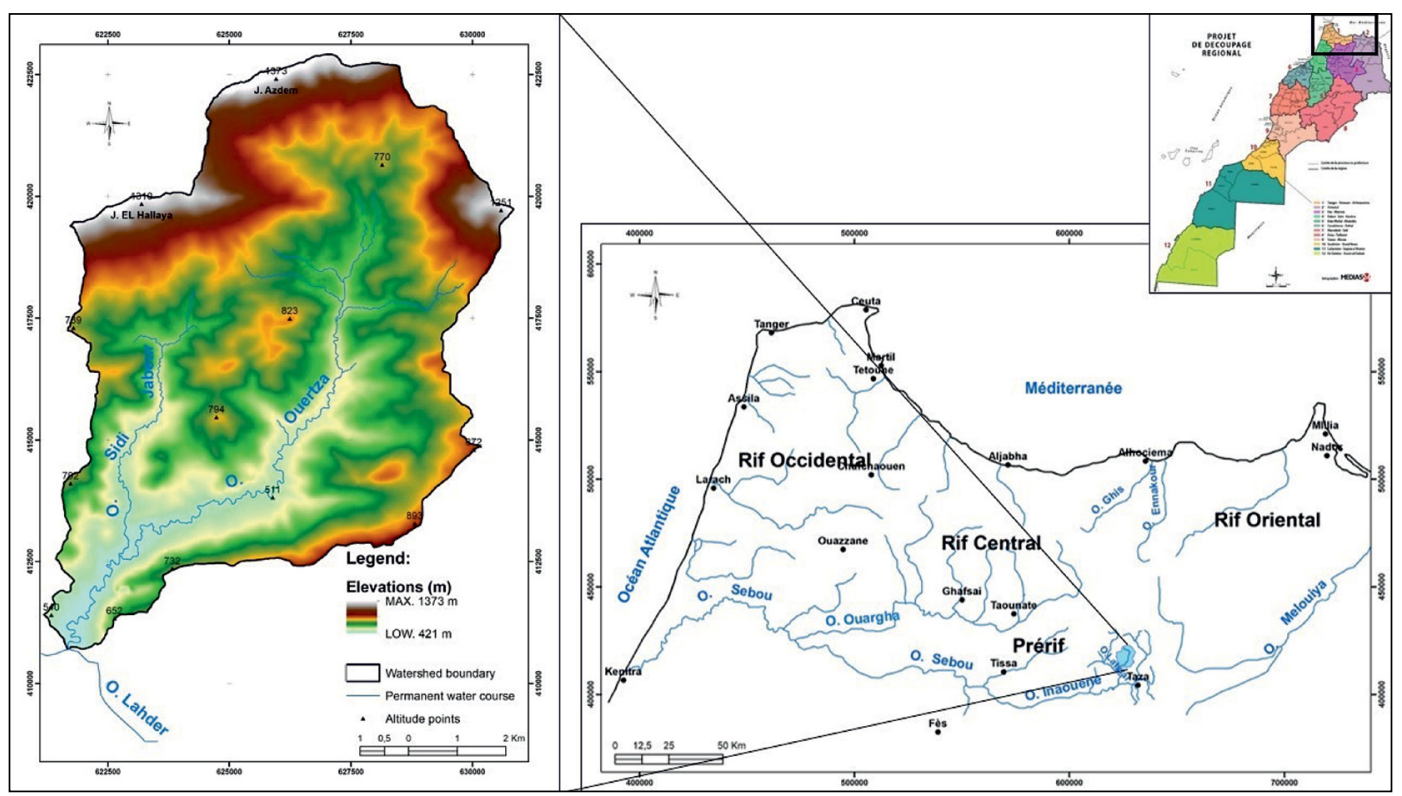

Elaboración propia

Figura 2. Distribución de las pendientes (A) y de las formaciones litológicas (B) en la subcuenca hidrográfica del Oued Ourtza

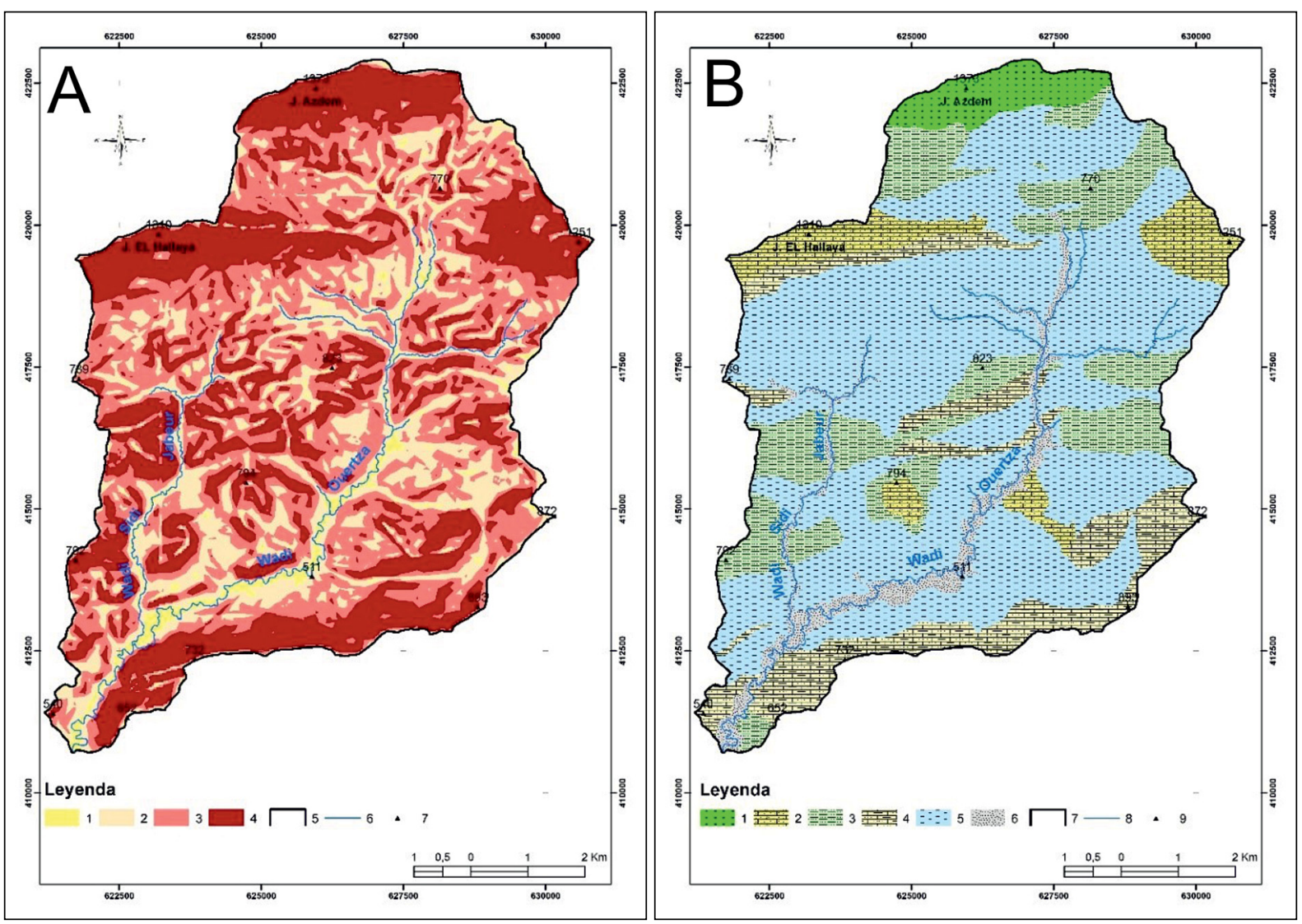

Leyenda mapa A: 1. 0-5\%, 2. >5-15\%, 3. >15-25\%, 4. > 25\%, 5. Límite de subcuenca hidrográfica, 6. Ríos permanentes, 7. Puntos de altitud. Leyenda mapa B: 1. Areniscas, 2. Areniscas y conglomerados con calizas, 3. Margas y areniscas, 4. Margo-calizas y arenisca, 5. Formaciones margosas, 6. Depósitos aluviales, 7. Límite de Subcuenca, 8. Ríos permanentes, 9. Puntos de altitud 
Los suelos poco evolucionados, están sometidos por la erosión a un desmantelamiento intenso que conlleva el empobrecimiento en coloides minerales y orgánicos. El bajo contenido en materia orgánica, así como el predominio de texturas limosas o limo-arenosas, les hacen más inestables y altamente sensibles al fenómeno de apelmazamiento superficial de las partículas finas del suelo por el impacto directo de las gotas de lluvia durante los episodios de lluvia de alta intensidad. Se generan así costras de "battance" que dificultan la permeabilidad de los suelos y favorecen la arroyada superficial. Los suelos arcillosos profundos, vertisoles o suelos con caracteres vérticos, manifiestan una estabilidad estructural importante; sin embargo, la fuerte presencia de arcillas expansivas conduce, en ciertas condiciones, a una degradación de su estructura. Durante el estío, su desecación favorece la formación de grietas superficiales que pueden alcanzar los horizontes profundos y condicionar los patrones de arroyada superficial, especialmente en otoño. En la estación húmeda, su saturación en agua implica cambios estructurales que se manifiestan mediante procesos de solifluxión muy frecuentes. Respecto a los suelos sobre aportes aluviales, son los más estables y profundos, al desarrollarse sobre terrazas y fondos de valle que bordean los cursos de agua (Tribak, 2000).

La subcuenca hidrográfica del Oued Ourtza presenta un carácter climático mediterráneo asociado a una fuerte irregularidad de las precipitaciones anuales y un enorme contraste estacional. El clima se caracteriza por lluvias muy intensas y concentradas en el tiempo con medias anuales de entre 681 y $599 \mathrm{~mm}$ para el periodo 1970-2013, según las estaciones metorológicas próximas de Had M’sila y Taza, situadas al NW y SE respectivamente, de la subcuenca. Para este mismo periodo, la estación de Taza registró precipitaciones máximas que alcanzaron los $1.125 \mathrm{~mm}$ en 2009-2010 y mínimas de $275 \mathrm{~mm}$ en 1994-1995. Por su parte la estación de Had M’sila, alcanzó un valor máximo de $1.411 \mathrm{~mm}$ durante el año 2009-2010 y un valor mínimo de $224 \mathrm{~mm}$ durante el año 1994-1995 (Figura 3). El estudio estadístico de las lluvias diarias registradas en la estación meteorológica de Taza durante el periodo 1979-2013, muestra que esta zona alcanza cantidades máximas de precipitación que habitualmente pueden superar los $100 \mathrm{~mm}$ al día y que originan dinámicas hidrológicas superficiales de enorme poder erosivo (Tribak, El Garouani $\&$ Abahrour, 2012a). Dos ejemplos de estos episodios extremos han sido los sucedidos el 30 de enero de 1987 en M`sila, donde los 101 mm recogidos ese día, supusieron el 33,3\% del total pluviométrico del mes; o los $113 \mathrm{~mm}$ registrados en Taza, el 14 de marzo de 2004, que alcanzaron ese día el 61,7\% del total de precipitaciones del mes. El análisis de la frecuencia de las cantidades máximas diarias registradas en esta misma estación muestra un aumento de las concernientes a episodios lluviosos con intensidades de entre 20 y $25 \mathrm{~mm} /$ día, con valores de entre 0,2 a 0,8 episodios para periodos de retorno de entre 2 y 5 años. Por su parte, los registros para intensidades de entre 70 y $80 \mathrm{~mm} /$ día alcanzan una recurrencia del orden de un episodio cada 10 años. En cuanto a los valores medianos, superan los $80 \mathrm{~mm} /$ día y son bastante raros, con un periodo de retorno que supera, en general, los 20 años (Tribak et al., 2012a).

En cuanto a la población, las densidades eran elevadas en la región en 2004 con valores que superaban los $100 \mathrm{hab} / \mathrm{km}^{2}$, y ello pese a la continua reducción generada por los movimientos migratorios (HCP, 2004). Esta presión demográfica es, sin duda, la responsable de la transformación de los paisajes forestales con aprovechamientos silvo-pastoriles en otros de tipo en mosaico, donde se imbrican las múltiples parcelas de cereal con un pastizal-matorral degradado. La historia contemporánea de la región durante el siglo XX, ha dado lugar a importantes mutaciones socio-espaciales que resultan en una serie de rupturas y perturbaciones que afectan a las estructuras preexistentes, así como al medio natural. Es esencialmente en este contexto, en el que se llevaron a cabo amplias acciones de desforestación que, desafortunadamente, solo eran posibles en áreas marginales o en laderas con pendientes pronunciadas. Los campesinos en crisis, lejos de preocuparse por las consecuencias de sus acciones, desmantelaron los bosques, ya degradados, que aún cubrían los macizos de areniscas ubicados en el norte de la región. La conquista de nuevas tierras de cultivo y la extensión de sus superficies, independientemente de la naturaleza de los terrenos y del grado de sus pendientes y sin tener en cuenta el peligro de erosión, fue el objetivo, en la búsqueda de medios de subsistencia, para una población desheredada y en crecimiento.

Los usos del suelo actuales muestran una extensión considerable de los cultivos anuales que ocupan los suelos profundos situados en los fondos de valle, así como los suelos esqueléticos conquistados sobre fuertes pendientes. Paradójicamente, los cultivos arbóreos no ocupan más que una pequeña proporción de la cuenca, aunque su superficie ha registrado una extensión importante durante las últimas décadas gracias a la oleicultura que se extiende incluso, por las laderas con pendientes pronunciadas. Las laderas se presentan, en su mayor parte, carentes de vegetación y puestas en cultivo, si bien el éxodo rural que 
afecta a la región desde los años 80 , está suponiendo un importante incremento de los terrenos incultos y abandonados que, cada vez, ocupan una mayor extensión en la región. De hecho, la falta de gestión de estas tierras de cereal abandonadas, sometidas a sobrepastoreo y a merced de los episodios de intensa precipitación, conduce a la compactación del suelo, la formación de costras y en suma a la impermeabilización de las superficies. Todo ello genera, sobre todo en las laderas soleadas y de suelo casi desnudo orientadas al sur, unas condiciones semiáridas que dificultan la revegetación y favorecen la concentración de la escorrentía. Se forman así surcos de arroyada que, sin mantenimiento ni laboreo, evolucionan en pocos años a cárcavas de erosión.

Figura 3. Precipitaciones anuales y media móvil quinquenal durante el periodo 1970-2016 en las estaciones meteorológicas de Taza (A) y Had M’sila (B)
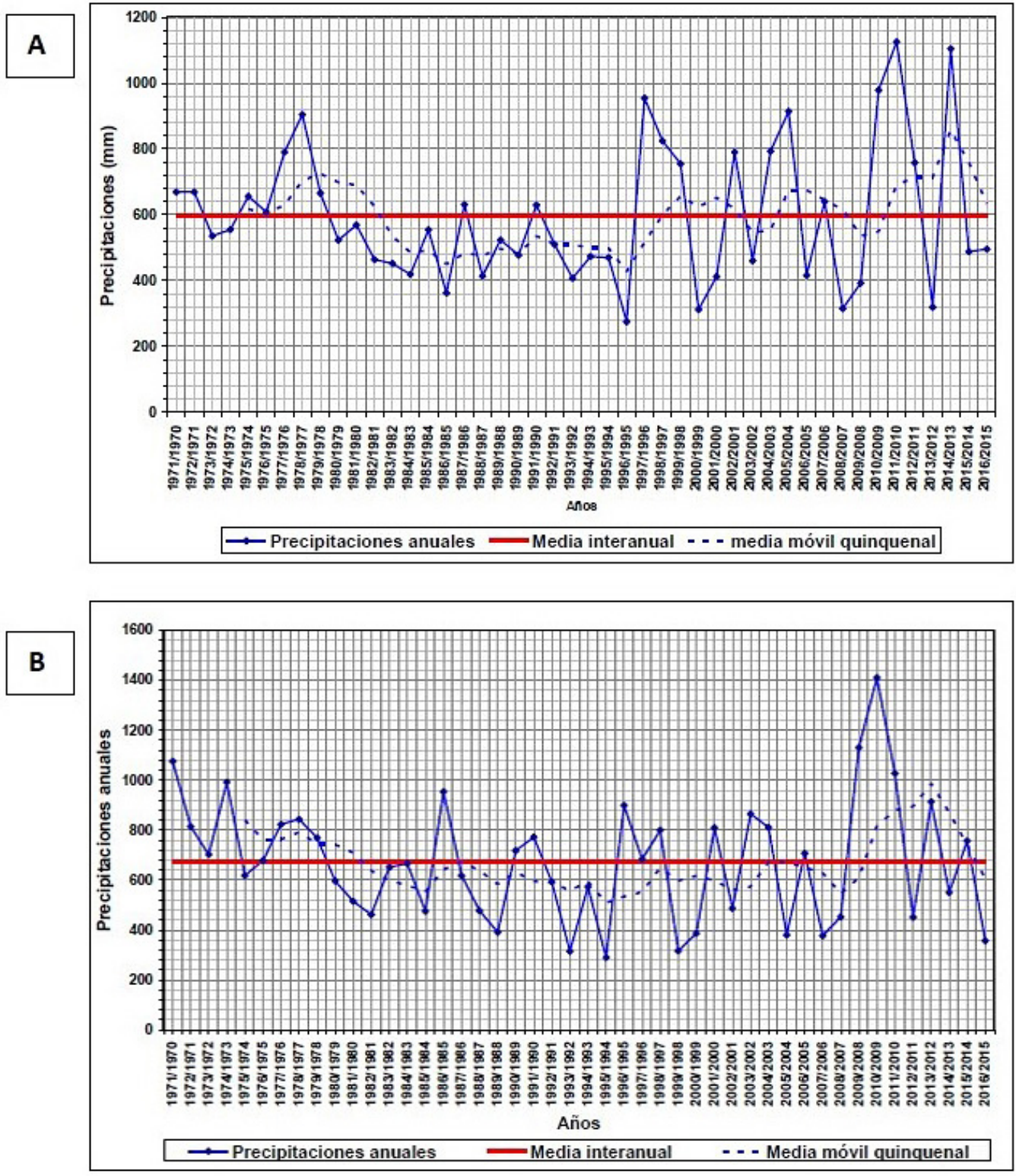

Fuente: Centros de trabajos agrícolas de Taza y Had M’sila. Elaboración propia

\subsection{Utilización de imágenes de teledetección para la cartografía de usos del suelo}

La identificación de la variación espacio-temporal de los usos del suelo en la zona de estudio se ha realizado a partir de la clasificación de las imágenes de satélite Landsat TM y Landsat ETM (imágenes del 18 de octubre de 2000, Landsat 7 y del 14 de octubre de 2014, Landsat 8). Los datos adquiridos 
fueron tratados y analizados mediante el programa de tratamiento de imágenes Erdas Imagine, siendo previamente georreferenciadas según la proyección cónica conforme de Lambert, calibradas para el sistema de coordenadas de referencia de la zona Merchich Norte (Sistema del Norte de Marruecos). De este modo se pudieron comparar las imágenes a partir de la selección de las partes correspondientes a la misma porción del territorio mediante el empleo de las coordenadas geográficas (Figura 4). Estos pretratamientos geométricos permitieron la integración de las imágenes de satélite en el SIG, facilitando los análisis requeridos. Además, se realizaron operaciones de mejora y combinación de canales para aumentar la calidad visual de las imágenes y aumentar la diferenciación de las clases temáticas de cara a su foto-interpretación. A partir de las consideraciones anteriores y de las características edáficas, de vegetación y uso agrícola de las parcelas de referencia observadas en el campo, se realizó una clasificación siguiendo las tres clases de ocupación del suelo más utilizadas en el modelo RUSLE para pronosticar la pérdida de suelo: tierras forestales, pastizales y tierras de cultivo. Pero distinguiendo en estas últimas entre cultivos anuales (cereal, girasol, etc.) y aquellos otros de vocación permanente como son los arbóreos (olivos, frutales, etc.). Junto a ello, se controló también las parcelas que dejaron de ser cultivadas y que fueron incorporadas al mapa de coberturas de suelo en la categoría de terrenos no cultivados/pastos. Por tanto, los usos del suelo se agruparon en las cuatro clases siguientes: terrenos no cultivados/pastos, cultivos anuales, cultivos arbóreos y bosque/reforestación.

Figura 4. Comparación de imágenes de la cuenca correspondientes al 18 de octubre de 2000 (A) y 14 de octubre de 2014 (B)

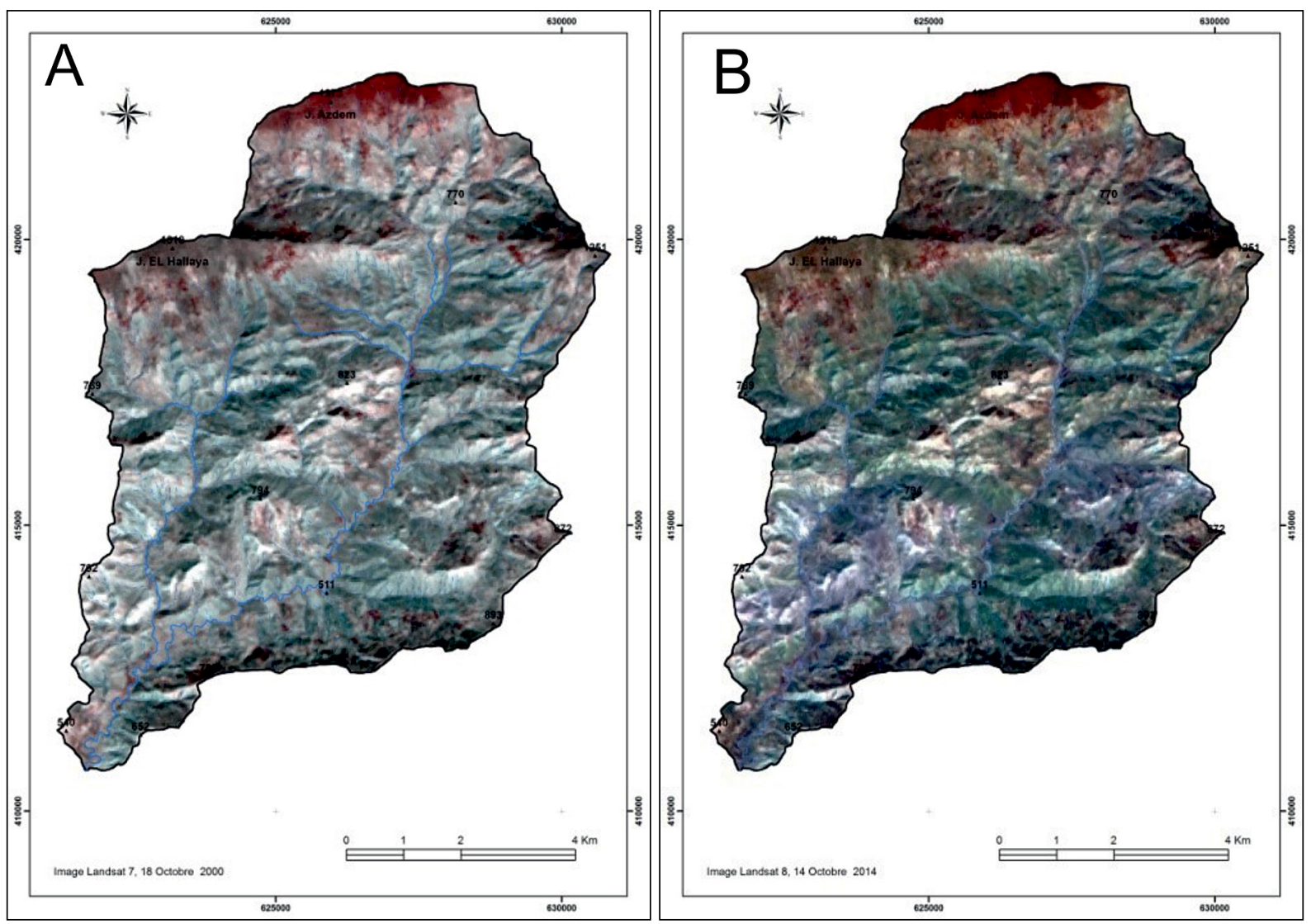

Fuente: Landsat 7, 2000 y Landsat 8, 2014. Elaboración propia

El enfoque se ha basado en la utilización de los datos de teledetección para conocer la distribución espacial de los factores de diferenciación de la erosión (usos del suelo, importancia de la cobertura vegetal, etc.), empleando SIG para las operaciones de análisis y modelización de los procesos de erosión. De este modo y con la finalidad de alcanzar el objetivo de cuantificar la erosión hídrica en la subcuenca hidrográfica, se procedió en primer lugar a una prospección del medio físico mediante el estudio de suelos en campo y laboratorio, para a continuación extraer la información temática de las imágenes de satélite. Finalmente, la explotación del modelo digital de terreno (MDT) permitió adquirir otros datos necesarios como las pendientes y la longitud de estas. Para ello se utilizó el software ArcGIS 10.1 para digitalizar 
todas las capas de información requeridas y luego para las operaciones de análisis espacial. Además, se empleó el programa Erdas Imagine para el procesamiento de imágenes de detección remota de cara a obtener la cartografía de usos del territorio. Para la modelización de los procesos de erosión del suelo, se optó por el uso del software IDRISI SELVA 17.

\subsection{Modelización de la erosión del suelo}

La cuantificación de la erosión hídrica se realizó mediante el modelo RUSLE (Revised Universal Soil Loss Equation) de Renard, Foster, Weesies, McCool \& Yoder (1997), integrado en el software Idrisi. Esta es una versión revisada de la ecuación USLE (Wischmeier $\&$ Smith, 1978), que permite estimar las cantidades de partículas de suelo suceptibles de ser erosionadas dentro de la cuenca y establecer la distribución espacial según las zonas más sensibles a la erosión sin tener en cuenta las dinámicas de transporte y sedimentación de los elementos terrígenos (Bonn, 1998). Este modelo se basa en una función lineal que involucra la combinación espacial de los diferentes parámetros que contribuyen a la erosión de los suelos. Por lo tanto, la tasa de erosión (A en $\mathrm{t} \cdot \mathrm{ha}^{-1} \cdot \mathrm{año}^{-1}$ ) es una función multiplicativa de la erosividad de las lluvias según su energía potencial (R), la resistencia del medio o la erodibilidad del suelo (K), el factor topográfico (LS), la cobertura vegetal y las prácticas de cultivo (C), y las medidas antierosivas (P), según la ecuación; $\mathrm{A}=\mathrm{R} \cdot \mathrm{K} \cdot \mathrm{LS} \cdot \mathrm{C} \cdot \mathrm{P}$, donde:

- El índice de erosividad de las lluvias (R), es igual a su energía cinética multiplicada por la intensidad máxima de las precipitaciones durante 30 minutos expresada en $\mathrm{cm}^{\cdot} \mathrm{h}^{-1}$. Este índice corresponde a los riesgos erosivos potenciales de una región dada, donde se manifieste la erosión laminar sobre una parcela sin vegetación con un 9\% de pendiente (Wischmeier $\&$ Smith, 1978). Algunos autores han desarrollado fórmulas alternativas que sólo utilizan la precipitación mensual y anual para determinar el factor R (Kalman, 1967; Arnoldus, 1980). En este trabajo, el cálculo del valor del índice R se basó en la fórmula de Rango \& Arnoldus (1987), utilizando los datos climáticos mensuales y anuales disponibles durante el período 1970-2013 en las estaciones meteorológicas de Had M'sila y Taza. De acuerdo con esta fórmula, R es del orden de 68,37 para la estación de Had M’sila y de 67,31 para la de Taza.

- El valor de K se obtuvo mediante el nomograma de Wischmeier (1976), utilizando el mapa de suelos del área de estudio y las propiedades de infiltración de los suelos de la región, según lo desarrollado por Tribak (2000), Tribak, El Garouani \& Abahrour (2009) y El Garouani, Chen, Lewis, Tribak \& Abahrour (2009). Además, se utilizaron los análisis concernientes a la textura y el contenido en materia orgánica de los horizontes superficiales $(0-20 \mathrm{~cm})$ y los datos de infiltración de los suelos obtenidos mediante lluvia simulada de $50 \mathrm{~mm}$ e intensidades de $80 \mathrm{~mm}^{\cdot \mathrm{h}^{-1}}$ en micro-parcelas en rampa de $1 \mathrm{~m}^{2}$. Antes de cada simulación se tuvo en cuenta el estado del suelo en la parcela, valorando si estaba cubierto o desnudo de vegetación y también si estaba abierta su superficie (presencia de macro-poros, fisuras o grietas de retracción) o cerrada (existencia de costras de "battance" o películas compactas por el pisoteo del ganado) y por tanto, con mínima capacidad de infiltración. Los valores del factor K oscilaron entre 0,22 para los suelos pardos calcáreos que ocupan, sobre todo, fondos y zonas con débiles pendientes; y 0,44 para los suelos regosólicos poco evolucionados ubicados en las zonas de badlands con exposición sur (Tabla 1).

Tabla 1. Erodibilidad de las unidades pedológicas (factor K)

\begin{tabular}{|l|c|}
\hline \multicolumn{1}{|c|}{ Tipos de suelos } & K métrico $\left(\mathbf{t} \cdot \mathbf{h a}^{-\mathbf{1}}\right)$ \\
\hline Suelos regosólicos poco evolucionados (de erosión) & 0,44 \\
\hline Suelos poco evolucionados de aporte aluvial & 0,39 \\
\hline Suelos poco evolucionados de aporte coluvial & 0,27 \\
\hline Vertisoles & 0,36 \\
\hline Suelos calcimagnésicos - rendzinas & 0,27 \\
\hline Suelos vérticos calcimagnésicos pardos & 0,22 \\
\hline
\end{tabular}

Fuente: Tribak 2000 y Tribak et al, 2009. Elaboración propia

- El factor topográfico (LS), depende a la vez tanto de la longitud de la pendiente como de su inclinación (Renard et al., 1997). Su cálculo para la subcuenca hidrográfica del Ourtza, se efectuó mediante el 
software IDRISI SELVA 17 que utiliza el MDT (Modelo Digital de Terreno), a partir del cual obtiene el grado de la pendiente, su orientación y longitud acumulada y, finalmente, el factor SL.

- El valor del factor C utilizado, se ha basado tanto en los resultados de estudios similares relativos a ciertas cuencas del Rif estudiadas con anterioridad (Kalman, 1967; Heusch, 1990; Tribak et al., 2009; El Garouani et al., 2009; Sadiki et al., 2004; Naimi et al., 2004), como en las imágenes de satélite y las observaciones de campo. Los valores asignados a los diversos modos de uso del suelo se sitúan entre 0,08 para los bosques abiertos que ocupan algunas cumbres en la zona alta de la subcuenca y 0,75 para los terrenos desnudos sin cultivar y ampliamente distribuidos sobre las pendientes más pronunciadas.

- El factor P varía entre 1, para las zonas sin medidas de conservación de suelos, y 0,1 para los terrenos muy manejados (Roose, 1996). Según observaciones realizadas en campo, los controles anti-erosivos son muy excepcionales en el área de estudio por lo que el valor 1 ha sido atribuido a toda la subcuenca y neutraliza el efecto de este factor.

Tras la determinación de todos los parámetros anteriores, la estimación y la cartografía de pérdidas de suelo se generó utilizando el modelo RUSLE integrado en el software IDRISI SELVA 17 (Lewis, Verstraeten \& Shu, 2005; Eastman, 2006).

\section{Resultados}

La comparativa diacrónica de las imágenes sobre el uso del suelo, denota una ligera pérdida del espacio natural representado por los bosques, frente al incremento de las zonas destinadas al cultivo arbóreo y las tierras sin cultivar, así como una reducción de las áreas destinadas al cultivo de cereal en beneficio de los cultivos arbóreos de frutales y olivar (Figura 5).

Figura 5. Mapas de usos del suelo en la subcuenca hidrográfica del Oued Ourtza durante los años 2000 (A) y 2014 (B)

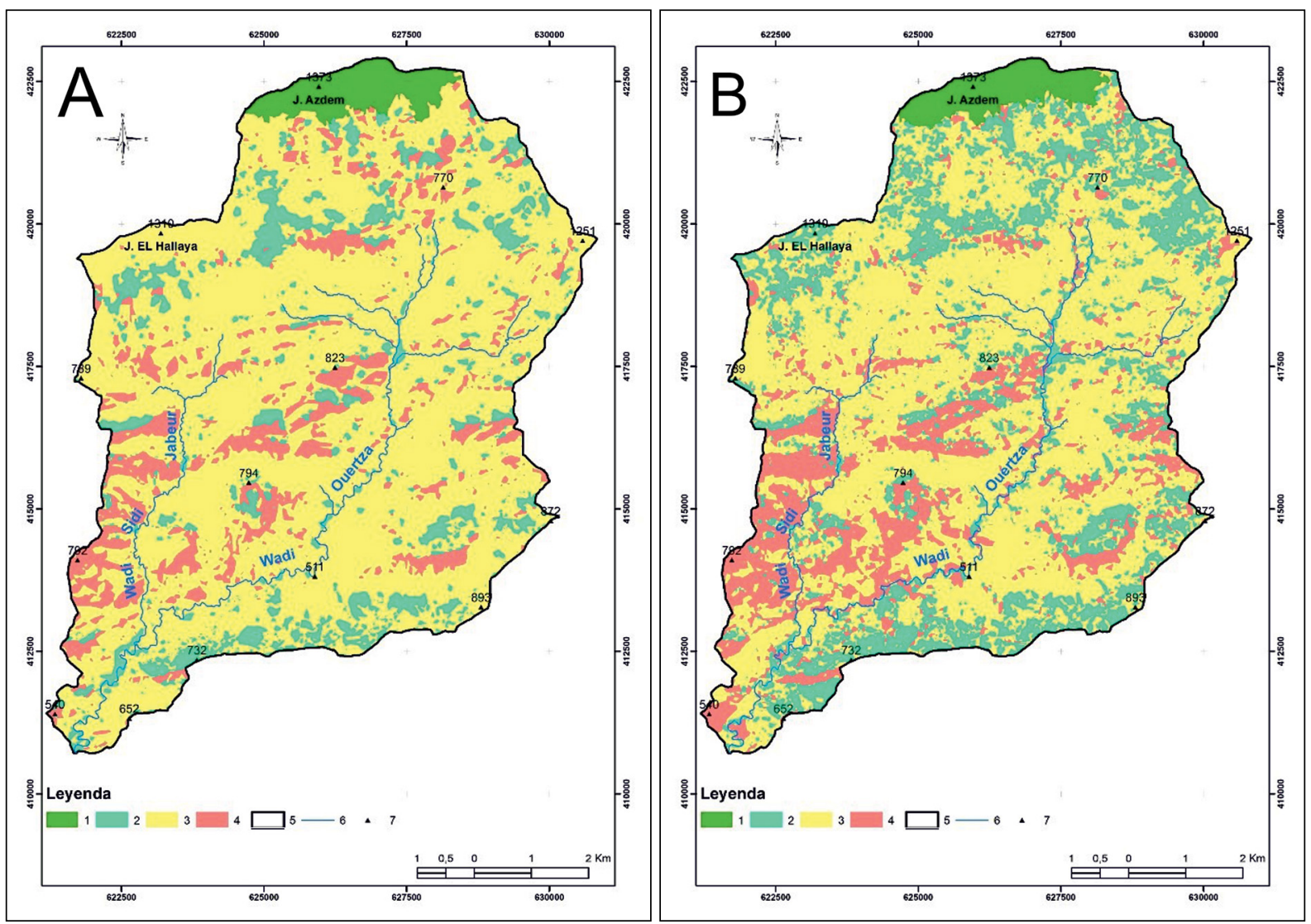

Leyenda: 1. Bosques, 2. Arboricultura, 3. Cultivos anuales, 4. Terrenos no cultivados/pastos, 5. Límites de subcuenca hidrográfica, 6. Ríos permanentes, 7. Puntos altimétricos. 


\subsection{Cambios en los usos del suelo}

Los 14 años trascurridos entre 2000 y 2014 (Tabla 2), se traducen en un uso del suelo, en la subcuenca hidrográfica del Oued Ourtza, donde prevalece el aumento de las zonas destinadas a cultivos arbóreos $(81,74 \%)$ y de los terrenos sin cultivar/pastos $(36,8 \%)$, frente a una reducción de las zonas con cultivos anuales, fundamentalmente cereal $(-17,22 \%)$ y bosques naturales o reforestados $(-5,19 \%)$. Esta tendencia ya ha sido constatada en la subcuenca del Oued Tleta en el Pre-Rif oriental, como parte de la cuenca hidrográfica del Oued Larbâa, donde su estudio diacrónico también puso de manifiesto el aumento de los cultivos arbóreos de frutales $(15,82 \%)$, los pastos y las tierras sin cultivar $(34,75 \%)$, frente a una reducción de las áreas destinadas a los cultivos anuales $(-8,52 \%)$ y sobre todo a los bosques, que lo hicieron en un -30,31\% (Tribak, Abahrour, El Garouani, Arari \& Amhani, 2017). En el caso de estudio, el importante aumento de las tierras no cultivadas/pastos, superior al 36\% en la subcuenca, está estrechamente vinculado al abandono de los terrenos agrícolas por el éxodo rural acelerado. Igualmente, las sequías recurrentes de las últimas décadas y la débil rentabilidad de la agricultura unidas a la evolución de las mentalidades, ha provocado un desinterés creciente en las generaciones más jóvenes por la actividad agrícola que fomenta el abandono rural en numerosos lugares de la región (Tribak, 2000). Ello ha supuesto una reducción de las superficies agrícolas e incluso, el abandono total o su dedicación a pastos de algunos campos no siempre marginales al incluir también tierras muy buenas sobre pendientes moderadas y las cuales alcanzaban en 2014 , algo más del $28 \%$ de la superficie total.

Tabla 2. Evolución diacrónica de los usos del suelo durante el periodo 2000-2014 en la subcuenca hidrográfica del Oued Ourtza

\begin{tabular}{|l|c|c|c|c|c|}
\hline \multirow{2}{*}{ Uso del suelo } & \multicolumn{2}{|c|}{ Año 2000} & \multicolumn{2}{c|}{ Año 2014 } & 2000-2014 \\
& (ha) & (\%) & (ha) & (\%) & ( \pm \% $)$ \\
\hline Bosque & 2,31 & 3,15 & 2,19 & 2,99 & $-5,19$ \\
\hline Cultivos arbóreos & 7,23 & 9,86 & 13,14 & 17,91 & 81,74 \\
\hline Cultivos anuales & 54,18 & 73,87 & 44,85 & 61,15 & $-17,22$ \\
\hline Sin cultivar/pastos & 9,62 & 13,12 & 13,16 & 17,95 & 36,80 \\
\hline Total & 73,34 & 100 & 73,34 & 100 & \\
\hline
\end{tabular}

Elaboración propia

\subsection{Cartografía y estimación de pérdida de suelo}

Los mapas de pérdida de suelo obtenidos a partir de los diferentes parámetros que conforman la RUSLE, permiten apreciar tanto la magnitud de las pérdidas en tierras de la región como su gran variabilidad entre sectores (Figura 6). La pérdida media ponderada según la superficie se estima en $43,41 \mathrm{t} \cdot \mathrm{ha}^{-1} \cdot$ año $^{-1}$, es decir, un total de 318.000 t $^{-}$año $^{-1}$ para toda la subcuenca en 2014. Estos resultados representan una producción importante de sedimentos que excede ampliamente el umbral de tolerancia de los suelos y que se relaciona, estrechamente, con la considerable extensión de los materiales margosos lábiles y el predominio de las pendientes fuertes y desnudas.

En cuanto a la distribución espacial de las pérdidas de suelo en la subcuenca para 2014, destaca igualmente la importancia del intervalo 20-32 $\mathrm{t}^{\cdot} \cdot \mathrm{ha}^{-1} \cdot \mathrm{año}^{-1} \mathrm{y}$ las superiores a las $32 \mathrm{t} \cdot \mathrm{ha}^{-1} \cdot \mathrm{anno}^{-1}$ que ocupan 23,23 y 19,48 ha respectivamente. Esto es, un $32,14 \%$ y un $26,95 \%$ de la superficie de la subcuenca. Este último intervalo es el que experimentó el mayor incremento entre 2000 y 2014, con un 51,48\% (Tabla 3). La preponderancia de estas dos clases debe entenderse vinculada con la extensión considerable de las tierras no cultivadas y dedicadas al pastoreo, donde la producción de sedimentos es excesiva. Así se confirma en la cartografía de usos y pérdida de suelos (Figuras 5 y 6), donde se aprecia que las zonas con altas pérdidas de suelo corresponden en términos de uso, principalmente a los terrenos no cultivados y abandonados del sector suroccidental, así como a las tierras de cultivo anual. Por su parte, las tierras actualmente en barbecho/pastizal y en las cuales las estructuras del suelo están significativamente más degradadas, son las que están sometidas a mayores coeficientes de escorrentía y, por tanto, las más favorables al aumento de los procesos de erosión y producción de sedimentos. 
Figura 6. Mapa de pérdida de suelos de la subcuenca hidrográfica del Oued Ourtza establecida mediante el modelo RUSLE para los años 2000 (A) y 2014 (B) en tha ${ }^{-1} \cdot a_{n} o^{-1}$
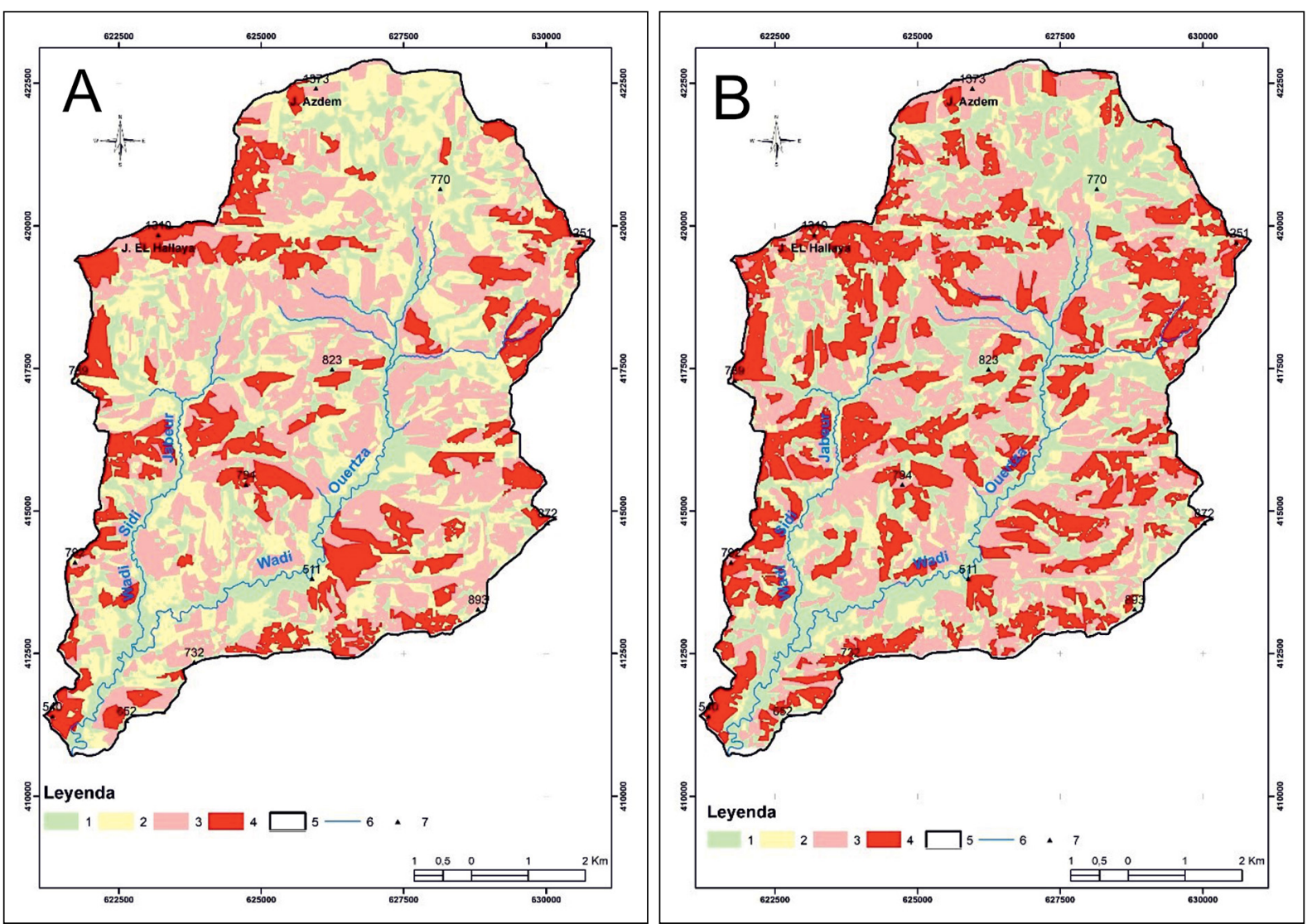

Leyenda: 1. 0-7, 2. >7-20, 3. >20-32, 4. >32, 5. Límites de subcuenca hidrográfica, 6. Ríos permanentes, 7. Puntos altimétricos Elaboración propia

Tabla 3. Evolución de los volúmenes de pérdida en suelo para la subcuenca hidrográfica del Oued Ourtza entre los años 2000 y 2014

\begin{tabular}{|c|c|c|c|c|c|}
\hline \multirow{2}{*}{$\begin{array}{c}\text { Tasas de erosión } \\
\qquad\left(\mathrm{t} \cdot \mathrm{ha}^{-1} \cdot \mathrm{año}^{-1}\right)\end{array}$} & \multicolumn{2}{|c|}{$\begin{array}{l}\text { Año } 2000 \\
\text { Superficie }\end{array}$} & \multicolumn{2}{|c|}{$\begin{array}{l}\text { Año } 2014 \\
\text { Superficie }\end{array}$} & \multirow{2}{*}{$\begin{array}{c}2000-2014 \\
( \pm \Delta \%)\end{array}$} \\
\hline & (ha) & $(\%)$ & (ha) & (\%) & \\
\hline$<7$ & 14,55 & 20,09 & 20,71 & 28,65 & 42,34 \\
\hline $7-20$ & 20,2 & 27,90 & 8,86 & 12,26 & $-56,14$ \\
\hline$>20-32$ & 28,8 & 34,25 & 23,23 & 32,14 & $-6,33$ \\
\hline$>32$ & 12,86 & 17,76 & 19,48 & 26,95 & 51,48 \\
\hline
\end{tabular}

Elaboración propia

La evolución de las pérdidas de suelo según su uso entre los años 2000 y 2014, muestra cómo las no cultivadas y sometidas al pastoreo son las que permanecen siempre a la cabeza en tasas de erosión con $65,81 \mathrm{t}^{\cdot} \mathrm{ha}^{-1} \cdot \mathrm{año}^{-1}$ en el 2000 y $81,55 \mathrm{t}^{\cdot} \mathrm{ha}^{-1} \cdot \mathrm{anno}^{-1}$, catorce años después. A tenor de las pérdidas de suelo por tipo de ocupación (Tabla 4), estas varían entre las 3,35 tha ha ${ }^{-1}$ año ${ }^{-1}$ en 2014 , como valor mínimo obtenido en las parcelas de bosque y las $81,55 \mathrm{t}^{\cdot} \mathrm{ha}^{-1} \cdot \mathrm{año}^{-1}$, como valor máximo registrado en las tierras no cultivadas y pastizales sobre badlands. Estas últimas se corresponden, por lo general, con regosoles o suelos erosionados de escaso desarrollo y situados sobre terrenos fundamentalmente margosos con pendientes elevadas que superan el $25 \%$ del territorio. Las áreas donde se implantan los cultivos anuales y la arboricultura manifiestan, igualmente en 2014, una fuerte susceptibilidad a la erosión con pérdidas anuales de 48,59 y 29,48 tha ${ }^{-1} \cdot a_{n} o^{-1}$ respectivamente. La reducción de las tasas de erosión en los terrenos destinados a los cultivos arbóreos en proporción a su extensión sobre la cuenca (18\%) se encuentra relacionada, muy pro- 
bablemente, con el notable incremento de las zonas destinadas a la arboricultura $(+81,74 \%)$; sobre todo en lo referente al olivar cuya extensión, en las últimas décadas, es patente sobre la mayor parte de las laderas.

Tabla 4. Evolución de la pérdida de suelo según los tipos de usos para la subcuenca hidrográfica del Oued Ourtza entre los años 2000 y 2014

\begin{tabular}{|c|c|c|c|c|c|c|}
\hline \multirow{2}{*}{ Uso del suelo } & \multicolumn{3}{|c|}{$\begin{array}{c}\text { Año } 2000 \\
\text { Superficie Pérdida suelo }\end{array}$} & \multicolumn{3}{|c|}{$\begin{array}{c}\text { Año } 2014 \\
\text { Superficie Pérdida suelo }\end{array}$} \\
\hline & (ha) & $(\%)$ & $\left(\mathrm{t} \cdot \mathrm{ha}^{-1} \cdot \mathrm{añno}^{-1}\right)$ & (ha) & $(\%)$ & $\left(\mathrm{t} \cdot \mathrm{ha}^{-1} \cdot \mathrm{año}^{-1}\right)$ \\
\hline Bosque & 2,31 & 3,15 & 3,17 & 2,19 & 2,99 & 3,35 \\
\hline Cultivos arbóreos & 7,23 & 9,86 & 17,41 & 13,14 & 17,91 & 29,49 \\
\hline Cultivos anuales & 54,18 & 73,87 & 60,62 & 44,85 & 61,15 & 48,59 \\
\hline Sin cultivar/ pastos & 9,62 & 13,12 & 65,81 & 13,16 & 17,95 & 81,56 \\
\hline
\end{tabular}

Elaboración propia

\section{Discusión}

La tendencia que muestra la subcuenca hidrográfica del Oued Ourtza al aumento de los cultivos arbóreos y los terrenos sin cultivar/pastos entre 2000 y 2014 (Figura 5, Tabla 2), confirma los resultados obtenidos en otras cuencas cercanas del Pre-Rif oriental (Tribak et al., 2017) y representa un fenómeno reciente y creciente que debe ser considerado como factor clave en los cambios del paisaje y la inestabilidad del medio de esta región del Pre-Rif durante el inicio del siglo XXI. Este fenómeno que comenzó en España a mediados del siglo XX, con el abandono de tierras marginales y continuó durante los años 80, sobre todo, a partir de la entrada en la Unión Europea (Rodriguez Juan \& Romero Díaz, 2016), aquí comienza en la década de los 80 y se mantiene hasta la actualidad. El proceso, por tanto, guardaría cierta similitud con lo acontecido en las zonas semiáridas mediterráneas donde la revegetación es un proceso lento, sobre todo con sobrepastoreo e intensas precipitaciones. Y no, con lo sucedido en las áreas de montaña mediterránea templado-húmeda donde, tras el abandono, se da un proceso de sucesión vegetal más rápido que disminuye las tasas de erosión respecto a las del uso agrícola previo (García-Ruiz, 2010).

En la subcuenca del Oued Ourtza, tras el abandono o el barbecho prolongado, se produce la rápida compactación de los campos desnudos con el consiguiente incremento de la degradación estructural de las antiguas superficies agrícolas, formación de costras y concentración de los flujos hídricos. Especialmente cuando se trata de terrenos intensamente surcados por el paso de los rebaños, y por tanto con coeficientes de escorrentía muy altos incluso para parcelas con pedregosidad y presencia de matas secas de maleza, que pudieran favorecer cierta rugosidad.

De manera similar, las pérdidas de suelo no agrícola que espacialmente son bajas $(17,95 \%)$ respecto a los campos aún trabajados (Tabla 4), registran tasas de erosión anuales más altas debido a la frecuencia de la escorrentía durante todo el año (Tribak et al., 2012a, b). A este respecto, las simulaciones de lluvia efectuadas sobre micro-parcelas en pendiente en la subcuenca limítrofe a la del Oued Tleta, han permitido constatar que la evolución de la escorrentía en parcelas aradas es débil en comparación con otros tipos de uso del suelo (Tribak et al., 2012b; Abahrour, Tribak \& El Garouani, 2015). De hecho, se comprueba que las tasas de infiltración siguen siendo muy altas en las tierras aradas y superan con creces las tasas registradas en tierras abandonadas, de pastos o en barbecho. Esto es aún más cierto para los vertisoles, ampliamente distribuidos en la subcuenca, así como para los suelos calcimagnésicos. Las tasas de infiltración en las tierras aradas generalmente se mantienen por encima de los $50 \mathrm{~mm} \cdot \mathrm{h}^{-1}$, incluso al final de la simulación. En cambio, descienden hasta los $15 \mathrm{~mm} \cdot \mathrm{h}^{-1}$ en terrenos abandonados o de pastos donde las superficies de los suelos cerradas son predominantes, lo que puede representar hasta el $30 \%$ de la extensión total de la subcuenca hidrográfica en otoño y el 75\% en invierno. Por lo tanto, los coeficientes de escorrentía permanecen muy altos en los vertisoles de las tierras abandonadas pudiendo alcanzar un máximo del 79\% (K max) a finales del verano y principios del otoño (Abahrour, 2009; Abahrour et al., 2015). Esto mismo ha podido comprobarse en las montañas argelinas, donde el coeficiente de escorrentía máximo puede alcanzar el $85 \%$ durante las fuertes lluvias que afectan a los terrenos desnudos y compactos (Roose et al., 1993). E incluso, mediante estudios experimentales, en la Cuenca del Telfifit (Argelia), 
donde se ha demostrado que trabajar los suelos arcillosos profundos puede reducir el coeficiente de escorrentía hasta en un 90\% (GTZ, 1996).

En la zona del Oued Ourtza, la tasa media de pérdida ponderada de suelo según la superficie se ha estimado con el modelo en $43,41 \mathrm{t}^{\cdot} \mathrm{ha}^{-1} \cdot \mathrm{anno}^{-1}$, lo que supone unas pérdidas anuales globales de suelo de 318.000 t $^{\cdot}$ año ${ }^{-1}$ para toda la subcuenca en 2014. Estos resultados hay que entenderlos en un entorno donde es considerable la extensión de los materiales margosos lábiles y el predominio de las pendientes fuertes y desnudas. Por lo que, en el contexto del Magreb, los resultados se encuentran en un rango medio-bajo en comparación con otros estudios previos (Tabla 5), aunque no lo suficientemente alejados de los máximos de hasta $60 \mathrm{t} \cdot \mathrm{ha}^{-1} \cdot \mathrm{anno}^{-1}$ que alcanzan las cuencas margosas periféricas carentes de vegetación del Pre-Rif con variaciones de entre 18 y $109 \mathrm{t}^{\cdot} \mathrm{ha}^{-1} \cdot \mathrm{año}^{-1}$, dependiendo de las laderas (Lelandais \& Fabre, 1996). A ello se añade en este caso, el papel de las actividades humanas y de los modos de ocupación del suelo como elementos más destacados para explicar la aceleración de los fenómenos erosivos y su distribución territorial. En especial a la hora de abordar la gran extensión que alcanzan las áreas de terrenos baldíos y badlands en la región y que obedece, fundamentalmente, al abandono de ciertos sectores por el fenómeno migratorio de las últimas décadas. La falta de trabajos de conservación de suelos frente a la erosión en ellos, provoca que las parcelas abandonadas se conviertan en lugares propensos a los procesos de arroyada y erosión (Maurer, 1991; Tribak, Arari, Abahrour, El Garouani \& Amhani, 2015). Las observaciones de campo ponen de manifiesto que, en realidad, las parcelas abandonadas, particularmente las de exposición sur, son las más deterioradas por la erosión y por tanto las que producen las mayores cantidades de sedimentos.

Tabla 5. Pérdida media de suelo en algunas cuencas hidrográficas Rifeñas

\begin{tabular}{|c|c|c|c|c|}
\hline $\begin{array}{l}\text { Cuenca-vertiente } \\
\text { (situación) }\end{array}$ & $\begin{array}{l}\text { Fuente } \\
\text { (método) }\end{array}$ & $\underset{\left(\mathrm{km}^{2}\right)}{\text { Superficie }}$ & Litología & $\begin{array}{l}\text { Pérdida media } \\
\left(\mathrm{t} \cdot \mathrm{ha}^{-1} \cdot \mathrm{anno}^{-1}\right)\end{array}$ \\
\hline $\begin{array}{c}\text { Oued Tleta, } \\
\text { (Pre-Rif oriental) }\end{array}$ & Tribak et al., 2009 (USLE) & 123 & $\begin{array}{c}\text { Margas, margo-calizas y } \\
\text { margas arenosas }\end{array}$ & 61 \\
\hline $\begin{array}{l}\text { Oued Nakhla } \\
\text { (Rif occidental) }\end{array}$ & Naimi et al., 2004 (Campo) & 111 & Margas y flyschs & 65 \\
\hline $\begin{array}{l}\text { Oued Boussouab } \\
\text { (Rif oriental) }\end{array}$ & Sadiki et al., 2004 (USLE) & 252 & $\begin{array}{c}\text { Pelitas negras, margas y } \\
\text { margo-calizas }\end{array}$ & 55 \\
\hline $\begin{array}{l}\text { Oued El Mellah } \\
\text { (Pre-Rif central) }\end{array}$ & El Aroussi et al., 2011 (RUSLE) & 34 & $\begin{array}{c}\text { Calizas, margas y areniscas } \\
\text { con conglomerados }\end{array}$ & 41 \\
\hline $\begin{array}{c}\text { Oued Kalaya } \\
\text { (Rif noroccidental) }\end{array}$ & $\begin{array}{c}\text { Khali, Ben, LechHab, } \\
\text { Raissouni, El Arrim, } 2016 \\
\text { (USLE) }\end{array}$ & 38 & $\begin{array}{l}\text { Flysch arcillo-calcáreo } \\
\text { y detrítico, formaciones } \\
\text { pelítico-areniscosas }\end{array}$ & 34 \\
\hline $\begin{array}{c}\text { Oued Sania } \\
\text { (Rif noroccidental) }\end{array}$ & $\begin{array}{c}\text { Tahiri, Tabyaoui, El Hammichi, } \\
\text { Tahiri \& El Hadi, } 2014 \\
\text { (RUSLE, USLE) }\end{array}$ & 177 & $\begin{array}{c}\text { Formaciones } \\
\text { margo-arcillosas } \\
\text { y areno-cuarcíticas }\end{array}$ & 47 \\
\hline $\begin{array}{c}\text { Oued Ourtza } \\
\text { (Pre-Rif oriental) }\end{array}$ & Este trabajo (RUSLE) & 73 & $\begin{array}{c}\text { Formaciones margosas y } \\
\text { margo-areniscosas }\end{array}$ & 43 \\
\hline
\end{tabular}

Elaboración propia

Con respecto al entorno del Mediterráneo occidental, la aplicación de los modelos USLE y RUSLE en diferentes subcuencas del río Segura (Murcia) o Guadalquivir, arrojan tasas de erosión de entre 30,2 y $80,4 \mathrm{t}^{\mathrm{h}} \mathrm{ha}^{-1} \cdot \mathrm{año}^{-1}$, siempre asociadas a episodios intensos de precipitación (Moreira Madueño, 1991; López Bermúdez, 2003; García-Ruiz, 2010). La similitud de estos datos con medidas experimentales y algunos ejercicios limitados de calibración del modelo RUSLE (Vanwalleghem, Infante, González, Soto, \& Alfonso, 2011; Alfonso, 2015), sugieren cierta viabilidad de su uso para la predicción. En los mismos términos se manifiestan las estimaciones de pérdidas de suelo, según el modelo RUSLE, obtenidas en las colinas de Terrefort Laugarain, en el sur de Francia. Aquí, en el sector sur del Valle de Hers con cultivos de cereal y pastos, el $81 \%$ de los valores de erosión son superiores a las $60 \mathrm{t}^{\cdot} \mathrm{ha}^{-1} \cdot \mathrm{año}^{-1}$ y el $70 \%$ están comprendidos entre las 31 y las $60 \mathrm{t}^{\cdot} \mathrm{ha}^{-1} \cdot \mathrm{año}^{-1}$, lo que representa el 51\% del área de la cuenca (Morscell \& Fox, 2004). Frente a estas cifras, el aumento de los cultivos arbóreos como el olivar, sobre todo si van acompañados de un manejo sostenible basado en el porcentaje de cobertura durante los periodos erosivos (labranza 
tradicional), pueden reducir ostensiblemente los problemas de erosión y la escorrentía si se implantan sobre suelos degradados o abandonados.

En cuanto a los resultados de este trabajo, no cabe duda que una validación rigurosa de los valores obtenidos, requiere de una correspondencia de estas estimaciones con mediciones realizadas en campo. Sobre todo, cuando los usos y cubiertas de suelo se obtienen mediante teledetección aunque se hayan validado en parte sobre el terreno. No obstante, para territorios relativamente extensos, con difícil acceso y carentes de otras fuentes de información, el modelo RUSLE se muestra como el más eficaz en sus resultados pues reduce el número de datos secundarios que requiere y su tratamiento mediante SIG (Renard et al., 1997; Van der Knijff et al., 2000). Desafortunadamente, en ausencia de un programa de seguimiento y de medida de la erosión en la región, sigue siendo imposible cuantificar la precisión de las estimaciones. No obstante, las mediciones en parcelas experimentales sobre laderas semiáridas realizadas en el noroeste

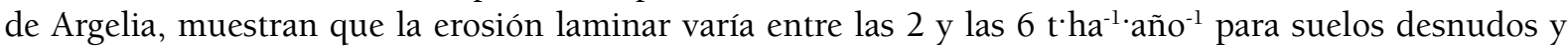
las 0,3 a $1,5 \mathrm{t}^{\cdot} \mathrm{ha}^{-1} \cdot \mathrm{anno}^{-1}$ en parcelas con cultivos tradicionales (Morscelli \& Fox, 2004). De igual modo, los resultados de las mediciones de erosión del suelo obtenidos en tierras cultivadas de la cuenca del Oued Nakhla (Rif occidental), arrojan un promedio de $1,15 \mathrm{t}^{\mathrm{t}} \mathrm{ha}^{-1} \cdot \mathrm{año}^{-1}$, lo que representa sólo el $6,2 \%$ del valor medio de degradación de los suelos que registra el embalse de la presa Nakhla por batimetría, que es del orden de 18,8 tha $\mathrm{a}^{-1} \cdot \mathrm{anno}^{-1}$ (Moukhchane, 2002). Por lo tanto, parece evidente que existe una discrepancia entre las mediciones en parcelas experimentales y las estimaciones basadas en modelos. Los modelos, generalmente, tienden a sobreestimar las tasas de erosión en ambientes mediterráneos donde la movilización de sedimentos se efectúa principalmente durante precipitaciones extremadamente intensas (Poesen \& Hooke, 1997; Wainwright \& Thornes, 2004; López-Vicente, Navas \& Mach, 2008). Además, los bajos valores de erosión obtenidos a escala de campo pueden estar relacionados con la ausencia de precipitaciones extremas durante el período experimental o simplemente con una variación de los factores relativos a las características de la litología, las pendientes, los suelos y sus modos de uso; parámetros que controlan enormemente la naturaleza de las arroyadas superficiales y la producción de sedimentos. Junto a esto, debe tenerse en cuenta también que la erosión, en las parcelas observadas, es esencialmente una erosión laminar y, por tanto, no concerniente a todos los procesos de erosión involucrados en la producción de sedimentos a escala de cuenca, tales como cárcavas, zonas de badlands y solifluxión. Por ello, los resultados de las medidas antes mencionadas, ya sea en Argelia o en el Rif marroquí, suministran información sobre el efecto de la puesta en cultivo o abandono de tierras en entornos montañosos, pero aún son insuficientes para identificar el conjunto de procesos de erosión que se combinan para producir las enormes cantidades de sedimentos registrados a escala de cuenca. Por lo tanto, en el caso de la cuenca del Oued Ourtza, los valores absolutos proporcionados por el modelo RUSLE pueden considerarse aceptables debido a la enorme extensión de las zonas de badlands y cárcavas como productoras principales de la mayoría de los sedimentos. De manera similar, la distribución espacial de las cantidades erosionadas a escala de cuenca, en función de los diferentes usos de los suelos, estarán próximas a la realidad por cuanto las medidas concernientes a la cantidad de suelos erosionados a partir de incisiones elementales generadas después de eventos lluviosos excepcionales, alcanzan tasas de erosión a nivel de hectárea de hasta 140 t, para suelos poco evolucionados y durante un evento de lluvia muy intenso (Tribak et al., 2012b).

\section{Conclusiones}

Se constata, una vez más, que los suelos y formaciones superficiales ubicados sobre terrenos esencialmente margosos manifiestan una gran susceptibilidad a la erosión, tanto más evidente cuanto más desprovistos están de vegetación y cultivos. La cartografía de la evolución de la ocupación del suelo a partir de datos de teledetección de una parte y de la evaluación cuantitativa de la erosión hídrica de otra, confirman que el Pre-Rif ha entrado en una tendencia regional a la sustitución de los cultivos tradicionales de cereal por los arbóreos, fundamentalmente frutales y olivos, junto a un importante abandono de las tierras $(36,8 \%)$ que duplica al registrado en el sureste de España para estas mismas fechas. Esto supone que, frente al incremento de los coeficientes de escorrentía en las zonas de cultivo anual abandonadas, sobre todo si hay sobrepastoreo, se registre una reducción en los nuevos cultivos de olivar que de alguna forma compensan los datos globales a nivel de cuenca. Ello explicaría que las pérdidas de suelo obtenidas mediante el modelo, superiores en promedio a las $40 \mathrm{t}^{\mathrm{h}} \mathrm{ha}^{-1} \cdot \mathrm{año}^{-1} \mathrm{y}$ muy por encima de los umbrales de tolerancia de pérdida de suelo de la región, se sitúen por debajo de la media del Rif marroquí. 
Aunque estas tasas -obtenidas mediante modelo RUSLE- no son extraordinarias a nivel del entorno mediterráneo ( $>50 \mathrm{t}^{\cdot} \mathrm{ha}^{-1} \cdot \mathrm{anno}^{-1}$ en los casos extremos de Europa), ni siquiera de la región del Rif marroquí ( $\left.>55 \mathrm{t}^{\cdot} \mathrm{ha}^{-1} \cdot \mathrm{anno}^{-1}\right)$; no es menos cierto que reflejan un importante ritmo de erosión que procede, en su mayoría, de los terrenos no cultivados y dedicados al pastoreo, sobre pendientes pronunciadas y con tasas superiores a las $80 \mathrm{t}^{\mathrm{t}} \mathrm{ha}^{-1} \cdot \mathrm{año}^{-1}$ en 2014 , así como a los cultivos anuales y barbechos $(61,15 \%)$.

Se confirma pues, que la producción de sedimentos es excesiva en el contexto de la comarca, lo que supone una amenaza, además de a la productividad de los suelos, para las infraestructuras situadas río abajo dentro de la cuenca del Oued Inaouene. No obstante, cabe señalar que, a falta de medidas de contención a adoptar por las administraciones implicadas, la extensión de los cultivos arboreos (frutales y fundamentalmente olivar), que no deja de ganar terreno en el conjunto de la subcuenca hidrográfica frente al cereal y otros cultivos anuales, representa por su mayor cobertura y permanencia temporal, un factor determinante a la hora de contener la evolución en las pérdidas de suelo, especialmente en ciertas laderas sometidas a ordenación y laboreo tradicional.

\section{Referencias}

Abahrour, M., Tribak, A., El Garouani, A. (2015). Dynamique du ruissellement et de l'érosion sur les terrains laboures du Prerif oriental: Cas du bassin de l'oued Telata. Dans: Actes du Deuxième Colloque international Eau \& Climat: Regards croisés Nord/Sud (pp. 99-105). Fès (Maroc).

Alfonso, J. (2015). Procesos erosivos en olivar en Andalucía a diferentes escalas: entendimiento, magnitude, implicaciones e intentos de control. En M.F. Moreno, J.R. Cañas (Eds.), Actas de las IV Jornadas de Ingeniería del Agua (pp. 59-69). Córdoba.

Arnoldus, H.M.J. (1980). Methodology used to determine the maximum average soil loss due to sheet and rill erosion in Morocco. Bulletin FAO, 34, 39-48.

Bonn, F. (1998). La spatialisation des modèles d'érosion des sols à l'aide de la télédétection et des SIG: Possibilités, erreurs et limites. Sécheresse, 9(3), 185-192.

De Santisteban, L.M., Casalí, J., López, J.J. (2006). Assessing soil erosion rates in cultivated areas of Navarre (Spain). Earth Surface Processes and Landforms, 31, 487-506. http://dx.doi.org/10.1002/ esp. 1281

DGTZ (Deutsche Gesellschaft für Technische Zusammenarbeit). (1996). Laménagement des zones marneuses dans les bassins-versants des montagnes de l'Atlas Tellien semi-aride (Algérie), GTZ im TZ-Verlag, Schriftenreihe.

Eastman, J.R. (2006). Idrisi Andes Manuel: Guide to SIG and Image Processing. Worcester: USA Clark University, Idrisi Production.

El Aroussi, O., Mesrar, L., El Garouani, A., Lahrach, A., Benabidate, L., Akdim, B., Jabrane, R. (2011). Predicting the potential annual soil loss using the revised universal soil loss equation (RUSLE) in the Wadi el malleh catchment (prerif, Morocco). Present Environment and Sustainable Development, 5(2), 5-15.

El Garouani, A., Chen, H., Lewis, L.A., Tribak, A., Abahrour, M. (2009). Evaluation du bilan d'érosion et de dépôt des sols au pré-Rif (Maroc) en utilisant le modèle RUSLE, la télédétection et analyse spatiale. Revue Internationale de Géomatique, 19(3), 303-317. https://doi.org/10.3166/geo.19.303-319

Francis, C. (1986). Soil erosion on fallow fields: an example from Murcia. Papeles de Geografía, 11, 21-28.

García-Ruiz, J.M. (2010). The effects of land use on soil erosion in Spain: a review. Catena, 81, 1-11. https:///doi.org/10.1016/j.catena.2010.01.001

García-Ruiz, J.M., Ruiz Flaño, P., Lasanta, P., Montserrat, G., Martínez Rica, J.P., Pardini, G. (1991). Erosion in abandoned fields, what is the problema? In M. Sala, J.L. Rubio, J.M. García-Ruiz (Eds.), Soils erosion studies in Spain (pp. 97-108). Logroño: Geoforma Ediciones.

García-Ruiz, J.M., Lasanta, T. (Eds.) (1994). Efectos geomorfológicos del abandono de tierras. Sociedad Española de Geomorfología. Logroño: Geoforma Ediciones.

Gartet, A. (1994). Morphogénèse et hydrologie dans le bassin-versant de l'oued Lebène (Rif Méridional et Prérif Central et Oriental, Maroc) (Thèse de doctorat en Géographie). Université d'Aix Marseille I, Institut de Géographie Aix-en-Provence. 
Gómez, J.A., Romero, P., Giráldez, J.V., Fereres, E. (2004). Experimental assessment of runoff and soil erosion in an olive grove on a Vertic soil in southern Spain as affected by soil management. Soil Use and Management, 20, 426-431. https://doi.org/10.1111/j.1475-2743.2004.tb00392.x

HCP (Haut Commissariat au Plan). (2004). Recensement général des populations et de l'habitat, Rabat.

Heusch, B. (1990). Lérosion dans le Pré-rif: une étude quantitative de l'érosion hydraulique dans les collines marneuses du Pré-rif occidental. Annales des recherches forestières, 12, 9-176.

Kalman, R. (1967). Essai d'évaluation pour le pré-Rif du facteur couverture végétale de la formule de Wischmeier de calcul de l'érosion. In Rapport de la Direction des eaux et forêts (12 p.), Rabat.

Kinnell, P.I.A. (2010). Event soil loss, runoff and the Universal Soil Loss Equation family of models. Review Journal of Hydrology. 385(1-4), 384-397. https://doi.org/10.1016/j.jhydrol.2010.01.024

Khali, L., Ben, H., LechHab, K., Raissouni, A., El Arrim, A. (2016). Cartographie Quantitative du Risque d'Erosion des Sols par Approche SIG/USLE au Niveau du Bassin Versant Kalaya (Maroc Nord Occidental). Journal of Materials Environmental Science 7(8), 2778-2795. Retrieved from http://www. jmaterenvironsci.com/Document/vol7/vol7_N8/291-JMES-2151-Khali\%20Issa.pdf

La Roca, N. (1984). La erosión por arroyada en una estación experimental (Requena, Valencia). Cuadernos de Investigaciones Geográficas, X, 85-98. https://doi.org/10.18172/cig.927

Leblanc, D. (1979). Etude géologique du Rif externe oriental au Nord de Taza (Maroc). Dans: Notes et Mémoires, Rabat: Service Géologique Marocain.

Lelandais, F., Fabre, G. (1996). Plan d'aménagement anti-érosif du bassin-versant de l'oued Ouergha (Maroc), Risques d'érosion et systèmes d'information géographique. Bull. Réseau Erosion. 16, 439-443.

Lewis, A.L., Verstraeten, G., Zhu, H. (2005). RUSLE applied in a GIS framework: Calculating the LS factor and deriving homogeneous patches for estimating soil loss. International Journal of Geographical Information Science, 19(7), 809-829. https://doi.org/10.1080/13658810500105705

López Bermúdez, F. (1989). Incidencia de la erosión hídrica en la desertificación de una cuenca fluvial mediterránea semiárida: cuenca del Segura. En: Degradación de zonas áridas en el entorno mediterráneo español (pp. 63-81). Monografías de la Dirección General de Medio Ambiente, Madrid: MOPU.

López Bermúdez, F. (2003). Evaluación de la erosión hídrica en las áreas receptoras de los embalses de la Cuenca del Segura. Aplicación de la USLE. En: F. López-Bermúdez, J.B. Thornes (Eds.). Estudios sobre Geomorfología del Sur de España (pp. 93-99). Murcia: Universidad de Murcia y University of Bristol.

Lopez-Vicente, M., Navas, A., Mach, J. (2008). Identifying erosive periods by using RUSLE factors in mountain fields of the Central Spanish Pyrenees. Hydrological and Earth System Sciences, 12, 523-535. Retrieved from http://www.hydrol-earth-syst-sci.net/12/523/2008/

MADREF (Ministère de l'Agriculture, du Développement rural et des Eaux et Forêts), (1994). Plan national d'aménagement des bassins-versants. Rapport de synthèse. Rabat.

MAMVA (Ministère de l'Agriculture et de la Mise en Valeur Agricole) (1993). Étude de préparation du plan national d'aménagement des bassins versants, Rabat.

Maurer, G. (1991). Les dynamiques agraires dans les montagnes rifaines et telliennes au Maghreb. Bulletin de l'Association de Géographes. Français, 68-4, 267-280. https://doi.org/10.3406/bagf.1991.1584

Merzouk, A., Fenjiro, I., Laouina, A. (1996). Cartographie de l'évolution de formes d'érosion dans le Rif Occidental (Maroc): étude multidate utilisant un SIG-Bassin versant. Bull Réseau Érosion, 16, 444-456.

Moreira Madueño, J.M. (1991). Capacidad de uso y erosión de suelos. Una aproximación a la evaluación de tierras en Andalucía. Sevilla: Junta de Andalucía.

Moreno de las Heras, M., Lindenberger, F., Latron, J., Lana, N., Llorens, P., Arnáez, J., Romero Díaz, A., Gallart, F. (2019). Hydro-geomorphological consequence of the abandonment of agricultural terraces in the Mediterranean region: Key controlling factors and landscape stability patterns. Geomorphology, 333, 73-91. https://doi.org/10.1016/j.gemorph.2019.02.014

Morscell, J., Fox, D. (2004). Une méthode de la cartographie du risque érosif: aplication aux collines de Terrefort laugarais, M@ppemonde 76 (2004.4). Retrieved from http://mappemonde-archive.mgm.fr/ num4/articles/art04404.pdf

Moukhchane, M. (2002). Différentes meéthodes d'estimation de l'érosion dans le bassin versant du nakhla (Rif occidental, Maroc). Bulletin Réseau erosion, 5, 255-266 
Naimi, M., Tayaa, M., Ouzizi, S. (2004). Cartographie de formes d'érosion dans le bassin-versant de Nakhla (Rif occidental, Maroc). Rev. Sécheresse 16, 79-82.

Panagos, P., Borrelli, P., Meusburger, K., Alewell, Chr., Lugato, E., Montanarella, L. (2015a). Estimating the soil erosion cover-management factor at the European scale. Land Use Policy 48, 38-50. http:// dx.doi.org/10.1016/j.landusepol.2015.05.02

Panagos, P., Borrelli, P., Poesen, J., Ballabio, C., Lugato, E., Meusburger, K, Montanarella, L., Alewell, Chr. (2015b). The new assessment of soil loss by water erosion in Europe. Environmental Science E Policy 54, 438-447. http://dx.doi.org/10.1016/j.envsci.2015.08.012

Poesen, J.W.A., Hooke, J.M. (1997). Erosion flooding and channel management in mediterranean environments of southern Europe. Progress in Physical Geography 21(2), 157-199. https://doi. org/10.1177/030913339702100201

Ramos, M. C., Porta, J. (1994). Rainfall intensity and erosive potentiality in the NE Spain Mediterranean area: results on sustainability of vineyards. Il Nuovo Cimento, 17, 291-299.

Rango, A., Arnoldus, H.M.G. (1987). Aménagement des bassins versants. In: Cahiers techniques de la FAO (1-11).

Renard, K.G., Foster, G.R., Weesies, G.A., Porter, J.P. (1991). RUSLE: revised universal soil loss equation. Journal Soil Water Conservation 46(1), 30-33.

Renard, K.G., Foster, G.R., Weesies, G.A., McCool, D.K., Yoder, D.C. (1997). Predicting soil erosion by water: A guide to conservation planning with the Revised Universal Soil Loss Equation (RUSLE), Washington, D.C.: Agricultural Handbook, $\mathrm{n}^{\circ} 703$.

Robledano, F., Romero Díaz, A., Belmonte, F., Zapata, V.M., Matínez, C., Martínez López, V. (2014). Ecogeomorphological consequences of land abandonment in semiarid mediterranean áreas: integrated assessment of physical evolution biodiversity. Agriculture, Ecosystems E Environment, 197, $222-242$. https://doi.org/10.1016/j.agee.2014.08.006

Rodriguez Juan, J.E., Romero Díaz, A. (2016). Evolución del abandono de tierras de cultivo en la comarca oriental de la Región de Murcia. Boletín de la Asociación de Geógrafos Españoles, 71, 9-29. https://doi. org/10.21138/bage.2272

Romero Díaz, M.A., López Bermúdez, F., Thornes, J.B., Francis, C.F., Fisher, G.C. (1988). Variability of overland Flow erosion rates in a semi-arid mediterranean environment under matorral cover, Murcia, Spain. Catena Supplement, 13, 1-11.

Romero Díaz, M.A. (2003). Influencia de la litología en las consecuencias del abandono de tierras de cultivo en medios mediterráneos semiáridos. Papeles de Geografía, 38, 151-165. Recuperado de https://revistas.um.es/geografia/article/view/46031

Roose, E. (1996). Land husbandry, components and strategy. In: Soils Bulletin FAO, 70, Rome. Retrieved from http://wwww.fao.org/docrep/T1765E).

Roose, E., Arabi, M., Brahamia, K., Chebbani, R., Mazour, M., Morsli, B. (1993). Érosion en nappe et ruissellement en montagne méditerranéenne algérienne Réduction de risques érosifs et intensification de la production agricole par la GCES: synthèse des campagnes 1984-1995 sur un réseau de 50 parcelles d'érosion. Cah. Orstom, sér. Pédol., XXVlll (2), 289-308.

Ruiz-Flaño, P. (1993). Procesos de erosión en campos abandonados del Pirineo. Logroño: Geoforma Ediciones.

Sadiki, A., Bouhlassa, S.J., Auajjar, J., Faleh, A., Macaire, J.J. (2004). Utilisation d'un SIG pour l'évaluation et la cartographie de risques d'érosion par l'équation universelle des pertes en sol dans le Rif oriental (Maroc): cas du bassin versant de l'oued Boussouab, Bulletin de l'Institut Scientifique Rabat, section Sciences de la Terre, 26, 69-79. Retrieved from http://www.israbat.ac.ma/wp-content/ uploads/2015/03/05-\%20Sadiki\%20et\%20al.\%20(69-79).pdf

Sala, M. (1988). Slope runoff and sediment production in two mediterranean mountain environments. Catena supplement, 12, 13-29.

Tahiri, M., Tabyaoui, H., El Hammichi, F., Tahiri, A., El Hadi, H. (2014). Evaluation et Quantification de l'Erosion et la Sédimentation à Partir des Modèles RUSLE, MUSLE et Déposition Intégrés dans un SIG. Application au Sous-Bassin de l'Oued Sania (Bassin de Tahaddart, Rif nord occidental, Maroc), European Journal of Scientific Research, 125(2), 157-178. 
Toubal, A. K., Achite, M., Ouillon, S., \& Dehni, A. (2018). Soil erodibility mapping using the RUSLE model to prioritize erosion control in the Wadi Sahouat basin, North-West of Algeria. Environmental Monitoring and Assessment, 190(4), 210. https://doi.org/10.1007/s10661-018-6580-z

Tribak, A. (2000). L'érosion hydrique en moyenne montagne du Prérif oriental (Maroc). Etude des agents et des processus d'érosion dans une zone de marnes tertiaires (Thèse Doctorat d'Etat).

Tribak, A., El Garouani, A., Abahrour, M. (2009). Évaluation quantitative de l'érosion hydrique sur les terrains marneux du PréRif oriental (Maroc): cas du sous-bassin de l'oued Tlata. Sécheresse. 20(4), 333-337. https://doi.org/10.1684/sec.2009.0205

Tribak, A., El Garouani, A., Abahrour, M. (2012a). L'érosion hydrique dans les séries marneuses tertiaire du Prérif oriental: agents, processus et évaluation quantitative. Revue Marocaine des Sciences Agronomiques et Vétérinaires, 1, 47-52. https://core.ac.uk/download/pdf/230579653.pdf

Tribak, A., El Garouani, A., Abahrour, M. (2012b). hydrous erosion in the catchment area of the wadi larbaa (Rif mountains, Morocco): agents, processe and modeling. Present Environment and Sustainable Development, 6(2), 7-20. https://www.researchgate.net/publication/286918757

Tribak, A., Arari, K., Abahrour, M., El Garouani, A., Amhani, Z. (2015). Quantitative assessment of the hydric erosion and the deposition in a marly catchment of the eastern Rif (case of wadi Tarmast, Morocco). Annals of Valahia University of Targoviste. Geographical Series, 15(2), 101-24. https://fsu. valahia.ro/images/avutgs/1/2015/2015150204.pdf

Tribak, A., Abahrour, M., El Garouani, A., Arari, K., Amhani, Z. (2017). Evaluation quantitative de l'érosion hydrique dans un environnement mediterranéen: cas de quelques basins marneux du prérif oriental maroc. In Eau et climat en Afrique du Nord et au Moyen-Orient (101-112). Târgoviste: Editions Transversal.

Van der Knijff, J., Jones, R., Montanarella, L. (2000). Soil erosion risk assessment in Europe: European Soil Bureau, European Commission, Belgium. Retrieved from https://www.preventionweb.net/files/1581 ereurnew2.pdf

Vanwalleghem, T., Infante, J., Gozález, M., Soto, D. \& Alfonso, J. (2011). Quantifying the effect of historical soil management on soil erosion rates in Mediterranean olive orchards. Agriculture, Ecosystems and Environment 142, 341-351. https://doi.org/10.1016/j.agee.2011.06.003

Van Wesemael, B., Rambaud, X., Poesen, J., Muligan, M., Cammeraat, E., Stevens, A. (2006). Spatial patterns of land degradation and their impacts on the water balance of rainfed treecrops: a case study in South East Spain. Geoderma, 133, 43-56. https://doi.org/10.1016/j.geoderma.2006.03.036

Wainwright, J., Thornes, J.B. (2004). Environmental Issues in the Mediterranean. Processes and Perspectives from the Past and Present (479 pp.). London: Routledge.

Wischmeier, W.H. (1976). Use and misuse of the universal soil loss equation. Journal of Soil and Water Conservation, 31(1), 5-9.

Wischmeier, W.H., Smith, D.D. (1978). Predicting rainfall erosion losses. In Guide for conservation planning. U.S. Department of Agriculture. Washington D.C.: Agriculture Handbook. Retrieved from http://naldc.nal.usda.gov/dowload/CAT79706928/PDF 